\title{
Síndrome de Gorlin-Goltz: Una presentación atípica
}

\author{
Gorlin - Goltz syndrome: A non typical presentation
}

\author{
Daniel Moyano $\mathrm{M}^{1}$, Luis Gondos G² , Eduardo Peirano $0^{3}$, Jaime Bermeo $\mathrm{S}^{4}$, Eduardo Sáez $\mathrm{C}^{4}$.
}

\section{RESUMEN}

El síndrome de Gorlin-Goltz o síndrome de carcinoma de nevo baso celular es un desorden autosómico dominante caracterizado principalmente por múltiples carcinomas baso celular, queratoquistes y defectos del desarrollo.

El queratoquiste odontogénico es una de las lesiones más constantes de este síndrome y con localización en el seno maxilar, se presenta habitualmente de manera asintomático y como hallazgo en exámenes radiológicos, sin embargo, puede presentarse de forma atípica, dando sintomatología secundaria a la compresión de estructuras vecinas, ya sea oculares o en la región facial. Además se debe realizar la evaluación genética y estudio de toda la familia.

El tratamiento quirúrgico realizado por equipo con experiencia en este territorio anatómico, debe ser el menos agresivo considerando su alta tasa de recurrencia local.

Palabras clave: Gorlin-Goltz, queratoquiste odontogénico.

\begin{abstract}
The Gorlin - Goltz syndrome carcinoma or basal cell nevus syndrome is an autosomal dominant disorder characterized mainly by multiple baso cellular carcinoma, queratocysts and developmental defects.

The odontogenic queratocyst is one of the most constant injuries of this syndrome and localization in the maxillary sinus, usually presenting asymptomatic and as a finding in radiological exams, however, may present atypically, giving symptoms related to compression neighboring structures either eye or facial region. In addition it should be performed genetic evaluation and study of the whole family.

The surgical treatment performed by experienced team in this anatomical area, should be the least aggressive considering the high rate of local recurrence
\end{abstract}

Key words: Gorlin-Goltz, odontogenic queratocyst.

\footnotetext{
1 Residente de Otorrinolaringología, Hospital Carlos van Buren, Universidad de Valparaíso.

2 Interno de Medicina, Universidad de Valparaíso.

3 Médico Cirujano, Hospital Quilpué, Universidad de Valparaíso.

${ }^{4}$ Otorrinolaringólogo, Hospital Carlos van Buren, Universidad de Valparaíso.
}

Recibido el 18 de marzo de 2015. Aceptado el 6 de octubre de 2015. 


\section{INTRODUCCIÓN}

El síndrome de Gorlin-Goltz (SGG) se caracteriza por una predisposición a desarrollar carcinomas baso celulares múltiples y alteraciones del desarrollo. Es una condición hereditaria causada por mutación en el gen supresor tumoral PTCH1, ubicado en el brazo largo del cromosoma 9 (9q22.3-q31), gen encargado del control del crecimiento y desarrollo normal de los tejidos. Esta mutación es transmitida de forma autosómico dominante con un alto grado de penetrancia (aproximadamente 97\%) y una expresividad variable. Fue reportado por primera vez, en 1894, por Jarisch y White, y descrito posteriormente, entre 1950 y 1960, por Gorlin y Goltz ${ }^{1,2}$.

La incidencia de esta enfermedad se estima en 1 en 50.000-150.000 en población general, que varían según la región ${ }^{3}$, siendo hombres y mujeres igualmente afectados ${ }^{4}$.

Los tumores que se desarrollan en estos pacientes son los carcinomas de nevo basocelular, los queratoquistes odontogénicos y los fibromas ováricos. El queratoquiste odontogénico es clasificado como una neoplasia benigna por la $0 \mathrm{MS}^{5} \mathrm{y}$ con frecuencia es la primera manifestación clínica del SGG. Suelen ser lesiones inicialmente asintomáticas que se diagnostican radiológicamente, con capacidad de crecer significativamente, gran potencial de recurrencia ${ }^{6}$, y multiplicidad de formas en su presentación, lo que define el abordaje quirúrgico, utilizando la técnica que cause la menor morbilidad?
Son necesarios criterios diagnósticos (Tabla 1), la histopatología y la evaluación genética para un diagnóstico precoz, basado en un enfoque multidisciplinario para el manejo de la condición y el pronóstico $0^{3,8}$.

\section{CASO CLÍNICO}

Mujer de 14 años, sin antecedentes mórbidos, consulta en el Servicio de Oftalmología del Hospital Carlos van Buren (HCVB) por dolor punzante en ojo izquierdo de 6 días de evolución, movimientos oculares normales pero dolorosos, hipostesia infraorbitaria, sin proptosis. El día previo a la consulta refiere aumento de volumen del ojo izquierdo, asociado a asimetría del nivel pupilar por elevación del mismo ojo, se decide por tanto hospitalización para estudio, solicitando tomografía computarizada contrastada de órbita (TC).

En el Servicio de Otorrinolaringología (ORL) del HCVB, se analizan antecedentes familiares de la paciente, determinando que su padre y un hermano tienen el diagnóstico de SGG, criterio clínico mayor $^{9}$ (Cma), este último que fue intervenido por un quiste maxilar y el informe anatomopatológico de la lesión indico queratoquiste odontogénico. El estudio por genetista solicitado a la paciente, considerando antecedentes familiares y los estigmas de este síndrome al examen físico, destacaron manos grandes y cortas (Cma). Dentro de los criterios clínicos menores ${ }^{9}$ destaca presentar frente amplia

Tabla $1^{4}$

\begin{tabular}{|c|c|}
\hline Criterios clínicos mayores (Cma): & Criterios clínicos menores (Cme): \\
\hline $\begin{array}{l}\text { - } \quad \text { Más de } 2 \text { carcinomas de nevo basocelular o un menor } \\
\text { - } 20 \text { años } \\
\text { - } \quad \text { Queratoquiste odontogénico maxilar } \\
\text { - } \quad \text { Calcificación ectópica de la hoz del cerebro } \\
\text { - } \quad \text { Anomalías del desarrollo esquelético } \\
\text { - } \quad \text { Familiar de primer grado con síndrome de Gorlin-Goltz }\end{array}$ & $\begin{array}{ll}\text { - } & \text { Macrocefalia ajustada por altura } \\
\text { - } & \text { Deformidad de Sprengel, pectus, y sindactilia } \\
\text { - } & \text { Puente de silla turca, hemivértebras } \\
\text { - } & \text { Fibroma/fibrosarcoma ovárico/ tumores virilizantes } \\
\text { - } & \text { Meduloblastoma } \\
\text { - } & \text { Prominencia frontoparietal, labio / paladar hendido, } \\
& \text { hipertelorismo ocular, prognatismo mandibular }\end{array}$ \\
\hline
\end{tabular}




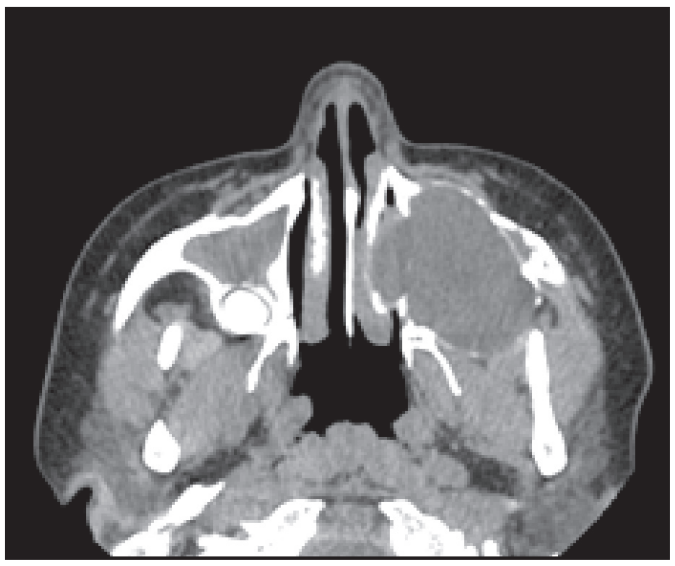

Figura 1. Expansión del seno maxilar izquierdo que contiene lesión hipodensa que no realza con contraste, la que mide $26 \mathrm{~mm}$ anteroposterior, $65 \mathrm{~mm}$ oblicuo y $50 \mathrm{~mm}$ transverso. En cara superior y lateral de seno maxilar izquierdo presenta inclusión de estructura de densidad ósea con remodelación ósea. Destaca a medial compromiso de fosa nasal ipsilateral.

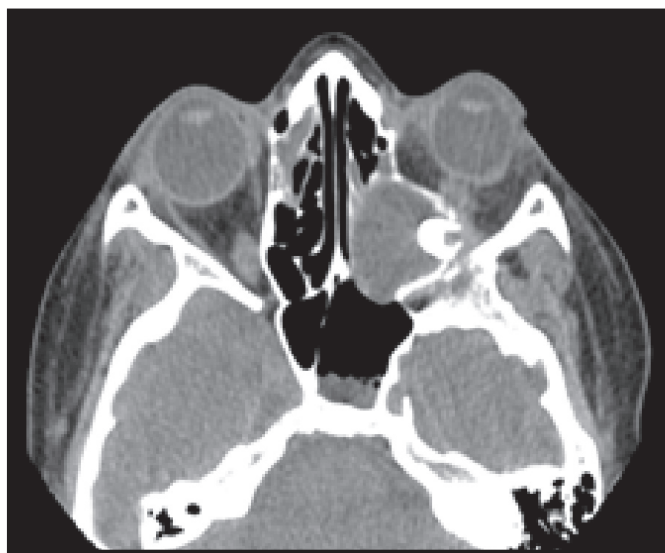

Figura 3. Seno maxilar derecho tamaño y morfología normal. Contenido de densidad de tejido blando en su interior. Presenta tabique óseo que incluye pieza dentaría, criterio clínico menor (Cme), conformando una estructura quística de $28 \mathrm{~mm}$ longitudinal x $16 \mathrm{~mm}$ transversal $\times 12 \mathrm{~mm}$ anteroposterior, la cual tiene bordes óseos bien definidos.

y abombada, puente nasal ancho, hipertelorismo, cuello corto y grueso, prognatismo, además de una depresión no dolorosa a la palpación de la región malar izquierda. Se decide tratamiento quirúrgico con técnica de Cadwell Luc a izquierda, extirpándose completamente el tumor, encontrándose en

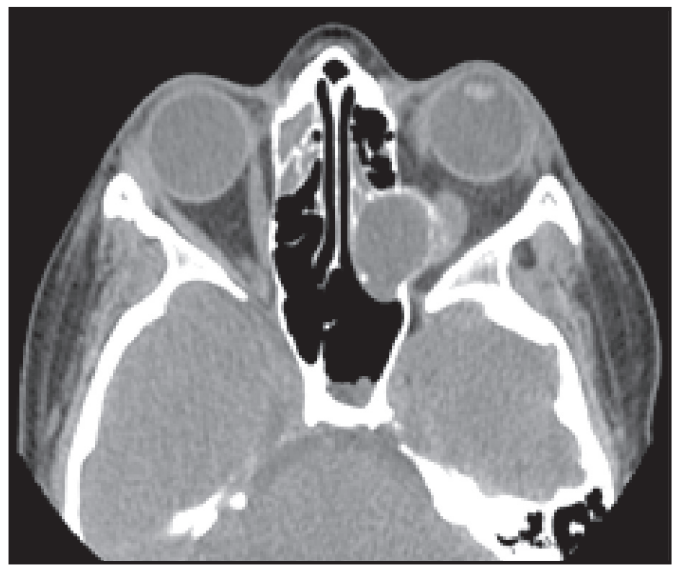

Figura 2. Elongación parcial del nervio óptico y una masa refringente que ocupa al piso de la órbita. Hacia lateral del seno maxilar izquierdo presenta lesión quística que contacta espacio masticador (masetero, pterigoides, y temporal) y que remodela levemente piso de la órbita.

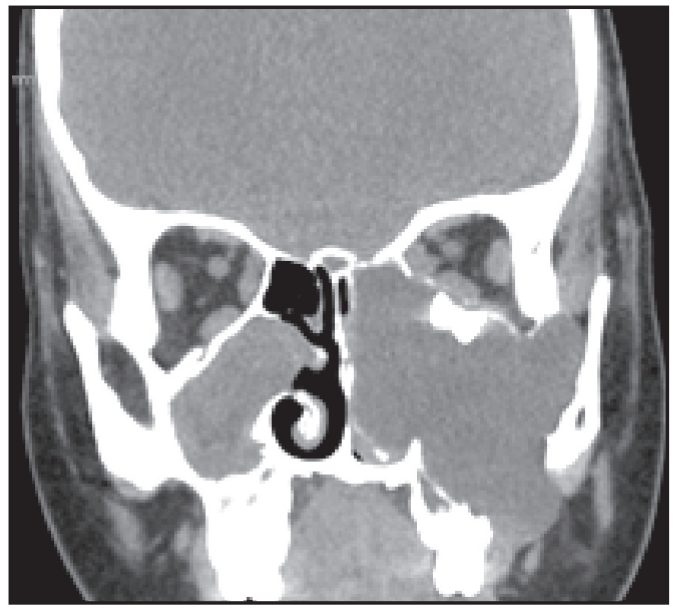

Figura 4. Corte coronal que presenta compromiso total de seno maxilar izquierdo con remodelación ósea de piso de órbita por extensión de masa refringente.

su interior pieza dentaria adherida a la cápsula y claros elementos de proceso séptico local. Por medio de cirugía endoscópica se realiza amplia antrostomía de seno maxilar derecho con salida de secreción blanquecina durante el procedimiento. El informe anatomopatológico de la pieza operatoria 


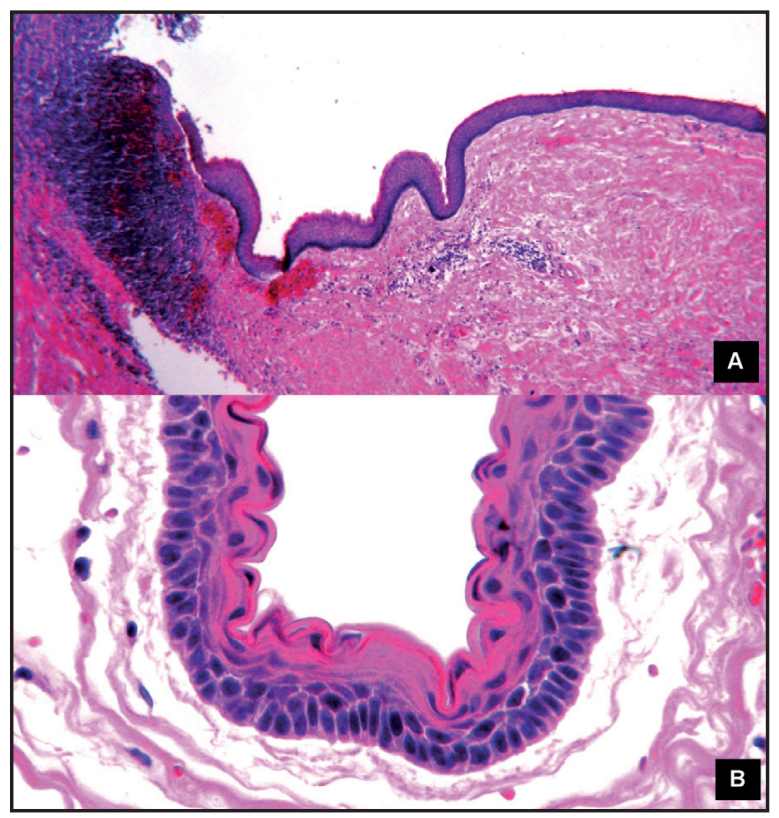

Figura 5. En A, revestimiento epitelial de quiste odontogénico, en un extremo en relación a exudado inflamatorio (HE 40x). En B se observa un epitelio de 6 capas de espesor, con estrato basal bien definido y superficie paraqueratótica ondulada, concordante con tumor queratoquístico odontogénico (HE 400x).

del seno maxilar izquierdo se informa como queratoquiste odontogénico, sin embargo, la pieza dentaria incluida en la lesión, sugiere del punto de vista anatomopatológico considerar como diagnóstico diferencial un quiste de origen dentario. La paciente no manifiesta molestias secundarias a la cirugía en el control posoperatorio, indicándose controles periódicos por la tendencia a la recurrencia de este tipo de lesión.

\section{DISCUSIÓN}

El SGG es una enfermedad poco frecuente caracterizada por una predisposición cancerígena cuyas manifestaciones otorrinolaringológicas son fundamentalmente la ocupación de los senos maxilares por queratoquistes odontogénicos y malformaciones craneofaciales.

Un criterio clínico relevante en el diagnóstico es el antecedente familiar de primer grado con la patología ${ }^{10}$, lo que para este caso permitió guiar la sospecha diagnóstica y el manejo, por ello es necesario el estudio familiar y el examen genético tras encontrarnos con un caso índice ${ }^{4,10}$.

La afectación del nervio infraorbitario manifestado por hipostesia de la región malar y de la musculatura extraocular, ambas secundarias a compresión por ocupación total del seno maxilar izquierdo es una manifestación que no está descrita como hallazgo habitual en un SGG, ni forma parte de los criterios clínicos mayores o menores. El enfoque terapéutico de los queratoquistes van desde medidas conservadoras a quirúrgicas; como la enucleación simple con curetaje, la enucleación con osteotomía periférica y la resección en bloque, esta última técnica es más agresiva pero con menor tasa de recurrencia ${ }^{10,11}$. El manejo propuesto con enucleación simple y curetaje, si bien tiene una mayor probabilidad de recurrencia, fue en este caso lo más adecuado a realizar, considerando la extensión de la lesión al piso orbitario, que impedía proponer una cirugía más agresiva, compatibilizando un criterio de eliminación y a la vez conservador de estructuras nobles, en una patología reconocida por sus recidivas. 


\section{BIBLIOGRAFÍA}

1. Mufaddel A, AlSabousi M, Salih B, AlHassani G, Osman 0. A Case of Gorlin-Goltz Syndrome Presented with Psychiatric Features. Behavioural Neurology 2014; Article ID 830874.

2. G Fini, E Belli, E Mici, P Virgiglio, L Moricca, L D`ıтRı, A. Leonardi. Nevoid basal cell carcinoma syndrome (Gorlin-Goltz syndrome). Case report. I/ Giornale di Chirugia 2013; 34(5-6): 176-9.

3. DN Mehta, N Raval H. Patadiya V. Tarsariya. Gorlingoltz syndrome. Ann Med Health Sci Res 2014; 4(2): 279-82.

4. A Agrawal, A Murari, S Vutukuri, A Sing. Gorlingoltz syndrome: case report of a rare hereditary disorder. Case Reports in Dentistry 2012; Article ID 475439.

5. M Shephard, H Coleman. Simultaneous adenomatoid odontogenic and keratocystic odontogenic tumours in a patient with GorlinGoltz syndrome. Aust Dent 2014; 59(1): 121-4.
6. Stoll. Significance of keratocysts in Gorlin-Goltz syndrome. Dtsch Zahnarztl Z 1985; 40(6): 525-8.

7. S Rosón, R González, Luis Naval, Jesús Sastre, M Muñoz, F Díaz. Síndrome de Gorlin-Goltz: serie de 7 casos. Revista Española de Cirugía Oral y Maxilofacial 2009; 31: 316-8.

8. M Kiwilsza, K Sporniak-Tutak. Gorlin-Goltz syndrome--a medical condition requiring a multidisciplinary approach. Medical Science Monitor 2012; 18(9): 145-53.

9. DGR Evans, EJ Ladusans, S Rimmer, LD Burnell, N Thakker, and PA Farndon. Complications of the naevoid basal cell carcinoma syndrome: results of a population based study. Journal of Medical Genetics 1993; 30(6): 460-4.

10. B.Taraku, K Baroudi, S Hanouneh, S Azzeghaiby, M NassanI. Possible recurrence of keratocyst in nevoid basal cell carcinoma syndrome: A review of literature. European Journal of Dentistry2013; 7 (1): 126-34.

11. F aL-Anazy, S Zakzouk. Otolaryngological manifestation of Gorlin Goltz syndrome. The Journal of Laryngology \& Otology 1997; 111(3): 286-9. 